\title{
AN INFLUENCE OF AEROBIC ACTIVITIES ON SPECIAL ENDURANCE OF STUDENTS IN GROUPS WITH A SPORTS ORIENTATION (SECTIONAL ACTIVITIES) OF PING-PONG
}

\author{
Grinko Vitaliy \\ Kharkiv Institute of Finance of Kyiv, National University of Trade and Economics, \\ Kharkiv, Ukraine \\ E-mail:vngrinko78@gmail.com
}

\begin{abstract}
APA Citation: Vitaliy, G. (2019). An influence of aerobic activities on special endurance of students in groups with a sports orientation (sectional activities) of ping-pong. Indonesian Journal of Learning and Instruction, 2(1), 27-34. doi: 10.25134/ijli.v2i01.1681.
\end{abstract}

Published: 01-04-2019

\begin{abstract}
The purpose of this study is experimentally to reveal the influence on the special endurance of aerobic activities (cross training and basic aerobics), which are included in the program of higher educational institutions of groups with sports orientation (sectional classes) Ping-Pong, and to explore the need to include these classes in the curriculum for physical education. The methods use analysis and generalization of literary sources, pedagogical observation, pedagogical experiment, modeling. In the experiment, 106 first-year students took part: 53 is control group and 53 is experimental. The result of this study is technique of revealing the influence of aerobic training on the special endurance of students of groups with a sports orientation is tested; the effectiveness of the experimental technique of training for increasing special endurance was developed and proved. So, it can be concluded that at this stage of the experiment, the effectiveness of the program was substantiated and proved with the inclusion of aerobic activities (cross training and basic aerobic elements) in the training groups on sporting orientation (sectional classes) Ping-Pong.
\end{abstract}

Keywords: aerobic classes; basic aerobics; cross training; sectional classes; simulated data; special endurance.

\section{INTRODUCTION}

The problem of increasing the effectiveness of physical education of student youth has been and is most significant in recent times. In theory and in practice, the issues of differentiation, individualization and profiling of education, the integration of the content of education, the ideas of optimization and modernization of the educational system were actively developed (Kudelko, Shcherbina, \& Pavlenko, 2003).

According to Kudelko and Korolinska (2006), it is necessary to abandon rigid normativeness, obligatory and authoritarianism, adjusting to the standard set from outside, to form an interested attitude of the student to the subject, to arouse interest in the possibility of building a healthy body, forming one's own health. All this indicates the need to find new ways to improve the physical, mental and moral state of student youth (Plowman \& Smith, 2011).

In our previous research on the results of the survey, students assessed the importance of developing physical qualities as follows: 1) endurance; 2) strength; 3) dexterity; 4) flexibility; 5) coordination; and 6) speed. Meanwhile, Grinko (2015) states that their own level of physical readiness was estimated as follows: 1) strength; 2) coordination; 3) speed; 4) flexibility; 5) dexterity; and 6) endurance. These facts show that students understand the important influence of endurance and its importance in solving the tasks of preparation for work, and they realize that it is this physical quality that most of them develop worse (Grinko, 2015; Kudelko \& Korolinska, 2006). 


\section{Grinko Vitaliy}

An influence of aerobic activities on special endurance of students in groups with a sports orientation (sectional activities) of ping-pong

Issues of improving the physical preparation of students in recent years have been considered in the works of a large number of researchers (Grinko, 2015; Kudelko, 2004). There are a lot of works where such physical quality as endurance is studied, but there are not enough works to improve special endurance in groups with a sports orientation (sectional classes), in particular Ping-Pong.

A work to improve the special endurance means of cross training and with the help of basic aerobics in groups with a sports focus (sectional classes) in recent years generally does not occur. Based on this, we have developed and justified a program based on cross training and elements of basic aerobics for groups with a sports orientation (sectional classes) Ping-Pong (Grinko, 2015; Kudelko, 2004), which should significantly improve physical quality such as special endurance.

The purpose of the research is experimentally to reveal the influence on the special endurance of aerobic activities (cross training and basic aerobics), which are included in the program of higher educational institutions of groups with sports orientation (sectional classes) Ping-Pong, and to explore the need to include these classes in the curriculum for physical education.

\section{METHOD}

The method of this study are analysis and generalization of literary sources, pedagogical observation, pedagogical experiment, modeling. In the experiment, 106 first-year students participated consist of 53 is control group and 53 is experimental. The research was carried out on the basis of the Simon Kuznets Kharkiv National University of Economics and Kharkov Institute of Finance of Kiev National Trade and Economic University. To test the hypothesis, the first stage was: studied the level of physical preparedness of students; developed and justified the program of physical training for students of groups with a sports orientation (sectional classes) Ping-Pong.
On the second stage: a comparative pedagogical experiment was conducted to check the effectiveness of the developed program. The experiment was conducted during the academic year from October 2015 to June 2016. Students of the control group were engaged in the program of a higher educational institution for groups with a sports orientation (sectional classes) Ping-Pong, and students of the experimental group on the program developed by us to increase the level of special endurance, which combines a program for special sports training (PingPong $-75 \%$ ) and aerobic exercise (cross training and elements of basic aerobics $25 \%)$. The program was based on the program of the higher educational institution for groups with a sports orientation (sectional classes) Ping-Pong and included in it for every fourth session - aerobic exercise (cross training and basic aerobics). By the middle of December, while weather conditions allowed, the students of the experimental group each fourth session were engaged in crosstraining in the open air, then moved to the hall where, in the experiment, they continued to engage in every fourth session already with basic aerobics, and at the end of March they again took to fresh air, where they continued to study every fourth session by cross training.

Kudelko (2004) said that at the beginning and at the end of the experiment, Ping-Pong competitions were held in the control and experimental groups, as checking the level of endurance in game sports, in particular in table tennis, is better manifested in competitive conditions (each pair played five games, in each batch was considered the number of mistakes made).

To check the level of special endurance at the beginning and at the end of the experiment, statistical and comparative analyzes of the experimental and control group data were made to find out how aerobic activities (cross training and basic aerobics) affected the level of special endurance. For this, Ashanin and 
Pyatisotskaya (2016) suggested that the pairwise regression model was used $\mathrm{F}$ Fisher and $t$ - Student criteria were analyzed for the linear regression equation (Novikova, 2011; Peters, 1991), linear coefficients of pair correlation, determination and average error of approximation were calculated (Dubnytskyi, 2011; Mandelbrot, 2004), estimated statistical significance of regression and correlation parameters (Lemeshko \& Pomadin, 2002; Weerahandi, 1995), residual dispersion is determined, confidence intervals are calculated (Nayman, 2009).

\section{RESULTS AND DISCUSSION}

As a result of using the pair regression method, such equations were found for the experimental group at the beginning of the experiment on October 2018. Calculation of the parameters of the linear regression equation for the experimental group at the beginning of the experiment is presented in the calculation table 1 .

We find estimates of the parameters of the regression equation:

$$
\begin{aligned}
& b=\frac{(\overline{x y})-\bar{x} \bar{y}}{\bar{x}^{2}-(\bar{x})^{2}}=\frac{18,67-5,74 \cdot 3}{11-(3)^{2}}=\frac{1,45}{2}=0,73 \\
& a=\bar{y}-b \bar{x}=5,74-0,73 \cdot 3=3,55
\end{aligned}
$$

We obtain the regression equation: at least one, the average number of errors $\hat{y}_{x}=a+b x$. increases on average by 0,73 :

On this basis, we see that with an $\hat{y} 1=3,55+0,73 \cdot 1=4,28$; increase in the number of games played by

Table 1. Calculation of the parameters of the linear regression equation for the experimental group at the beginning of the experiment (October)

\begin{tabular}{ccccc}
\hline № i/o & $\mathbf{X}$ & $\mathbf{Y}$ & $\hat{y}_{x}$ & $y-\hat{y}_{x}$ \\
\hline 1 & 1 & 4,24 & 4,28 & $-0,04$ \\
2 & 2 & 5,0 & 5,01 & $-0,01$ \\
3 & 3 & 5,9 & 5,74 & 0,16 \\
4 & 4 & 6,49 & 6,47 & 0,02 \\
5 & 5 & 7,09 & 7,2 & $-0,11$ \\
Total & 15 & 28,72 & 28,7 & 0,02 \\
Average & 3 & 5,74 & 5,74 & 0,004 \\
\hline
\end{tabular}

Here and below: $\mathrm{X}$ - set number, $\mathrm{Y}-$ parameters. number of errors, $\hat{\mathrm{y}}_{\mathrm{X}}, \mathrm{y}-\hat{\mathrm{y}}_{\mathrm{X}}-$ additional values for finding linear regression

$$
\begin{aligned}
& \hat{y} 1=3,55+0,73 * 1=4,28 ; \\
& \hat{y} 2=3,55+0,73 \cdot 2=5,01 ; \\
& \hat{y} 3=3,55+0,73 \cdot 3=5,74 ; \\
& \hat{y} 4=3,55+0,73 \cdot 4=6,47 ; \\
& \hat{y} 5=3,55+0,73 \cdot 5=7,2 .
\end{aligned}
$$

The tightness of the linear connection is estimated by the correlation coefficient:

$$
\begin{gathered}
\sigma_{x}^{2}=\overline{x^{2}}-\bar{x}^{2} ; \sigma_{x}=\sqrt{\sigma_{x}^{2}} ; \\
\sigma_{y}^{2}=\overline{y^{2}}-\bar{y}^{2} ; \sigma_{y}=\sqrt{\sigma_{y}^{2}} ; \\
r_{x y}=b \frac{\sigma(x)}{\sigma(y)}=0,73 \frac{1,41}{1,04}=0,99 .
\end{gathered}
$$

Since the value of the correlation coefficient is greater than 0.9 , there is a fairly close linear relationship between the number of played set and the number of 


\section{Grinko Vitaliy}

An influence of aerobic activities on special endurance of students in groups with a sports orientation (sectional activities) of ping-pong

errors committed. We find the coefficient of determination: $r_{x y}^{2}=0,99^{2}=0,98$.

As can be seen from the equation, the

This means that $98 \%$ of the variation in the errors $(y)$ is due to the variation of the factor $\mathrm{x}$ - the number of played sets.

Having the regression equations $\hat{y}_{x}=5,74+0,73 \cdot x, \mathrm{t}$ is possible to predict the number of errors for the sixth sets:

$$
\hat{y}_{6}=5,74+0,73 \cdot 6=7,93 \text {. }
$$
error for the sixth set will increase slightly, but the calculation error does not exceed $10 \%$. The calculation of the parameters of the linear regression equation for the experimental group at the end of the experiment on May 2018 is presented in the calculation table 2.

Table 2. Calculation of the parameters of the linear regression equation for the experimental group at the end of the experiment (May)

\begin{tabular}{ccccc}
\hline № i/o & $\mathbf{X}$ & $\mathbf{Y}$ & $\hat{y}_{x}$ & $y-\hat{y}_{x}$ \\
\hline 1 & 1 & 4,02 & 4,1 & $-0,08$ \\
2 & 2 & 4,45 & 4,4 & 0,05 \\
3 & 3 & 4,81 & 4,7 & 0,1 \\
4 & 4 & 5,04 & 5 & 0,04 \\
5 & 5 & 5,19 & 5,3 & $-0,11$ \\
Total & 15 & 23,51 & 23,5 & 0 \\
Average & 3 & 4,7 & 4,7 & - \\
\hline
\end{tabular}

Here and below: $\mathrm{X}$ - set number, Y number of errors, $\hat{\mathrm{y}}_{\mathrm{x}}, \mathrm{y}-\hat{\mathrm{y}}_{\mathrm{X}}-$ additional values for finding linear regression parameters.

Thus, having the regression equation $\hat{y}_{x}=3,8+0,3 \cdot x$, we can predict the number of errors for the sixth set:

$\hat{y} 6=3,8+0,3 \cdot 6=5,6$.
As can be seen from the equation, the error for the sixth set will increase slightly, but the calculation error does not exceed $10 \%$.

After statistical processing of the data, let us make a comparative analysis of the numerical data of the experimental group for October and May in the figure 1.

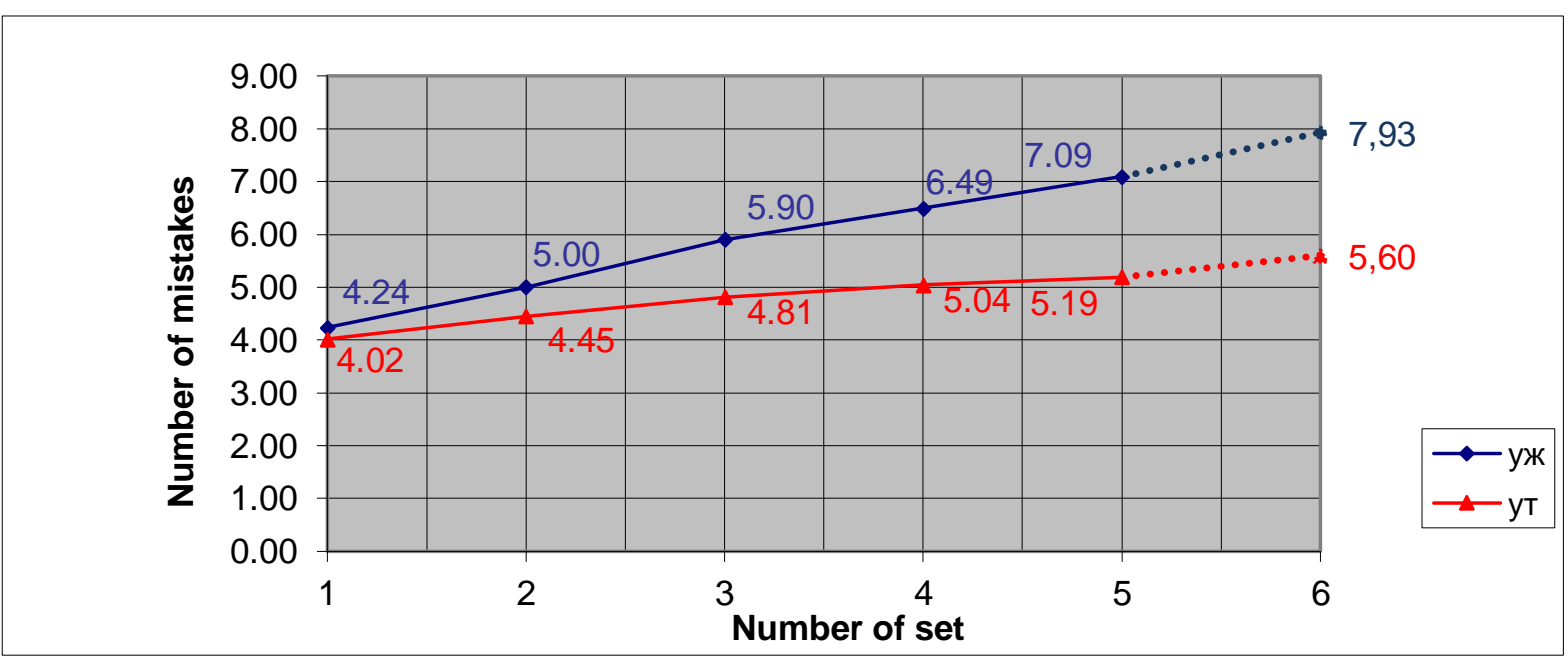

Figure 1. Comparative analysis of the numerical data of the experimental group when playing table tennis in October and May: уж - data for October, ym-data for May

As we see, the numerical data of the experimental group at the end of the experiment have a significant improvement: during the first set by 0,22 ; during the second 
by 0,55 ; during the third by 1,09 ; during the fourth by 1,02 ; during the fifth by 1,9 ; with a projected sixth set of 2,33. The level of reliability of the model is high, since the average error of approximation does not exceed $5 \%$ (in October, $\mathrm{A}=1,14 \%$, and in May $\mathrm{A}=1,66 \%$ ).
Calculation of the parameters of the linear regression equation for the control group at the beginning of the experiment on October 2018 is presented in the calculation table 3.

Table 3. Calculation of the parameters of the linear regression equation for the control group

\begin{tabular}{ccccc}
\multicolumn{5}{c}{ at the beginning of the experiment (October) } \\
\hline № i/o & $\mathbf{X}$ & $\mathbf{Y}$ & $\hat{y}_{x}$ & $y-\hat{y}_{x}$ \\
\hline 1 & 1 & 4,25 & 4,3 & $-0,05$ \\
2 & 2 & 5,11 & 5,02 & $-0,09$ \\
3 & 3 & 5,79 & 5,74 & 0,05 \\
4 & 4 & 6,42 & 6,46 & $-0,04$ \\
5 & 5 & 7,15 & 7,18 & $-0,03$ \\
Total & 15 & 28,72 & 28,7 & 0,02 \\
Average & 3 & 5,74 & 5,74 & 0,004 \\
\hline
\end{tabular}

Thus, having the regression equation $\hat{y}_{x}=3,58+0,72 \cdot x$, we can predict the number of errors for the sixth set:

$$
\hat{y}_{6}=3,58+0,72 \cdot 6=7,9 \text {. }
$$

As can be seen from the equation, the error for the sixth set will increase slightly, but the calculation error does not exceed $10 \%$.

Calculation of the parameters of the linear regression equa tion for the control group at the end of the experiment on May 2018 is presented in the calculation table 4.

Table 4. Calculation of the parameters of the linear regression equation for the control group at the end of the experiment (May)

\begin{tabular}{ccccc}
\hline № i/o & $\mathbf{X}$ & $\mathbf{Y}$ & $\hat{y}_{x}$ & $y-\hat{y}_{x}$ \\
\hline 1 & 1 & 3,94 & 3,99 & $-0,05$ \\
2 & 2 & 4,43 & 4,44 & $-0,01$ \\
3 & 3 & 4,94 & 4,9 & 0,04 \\
4 & 4 & 5,4 & 5,36 & 0,04 \\
5 & 5 & 5,79 & 5,82 & $-0,03$ \\
Total & 15 & 24,5 & 24,51 & $-0,01$ \\
Average & 3 & 4,9 & 4,9 & - \\
\hline
\end{tabular}

Thus, having the regression equation $\hat{y}_{x}=3,52+0,46 \cdot x$, we can predict the number of errors for the sixth set:

$$
\hat{y}_{6}=3,52+0,46 \cdot 6=6,28 \text {. }
$$

As can be seen from the equation, the error for the sixth set will increase slightly, but the calculation error does not exceed $10 \%$.

After statistical processing of the data, let us make a comparative analysis of the numerical data of the experimental group for October and May in the figure 2. 
An influence of aerobic activities on special endurance of students in groups with a sports orientation (sectional activities) of ping-pong

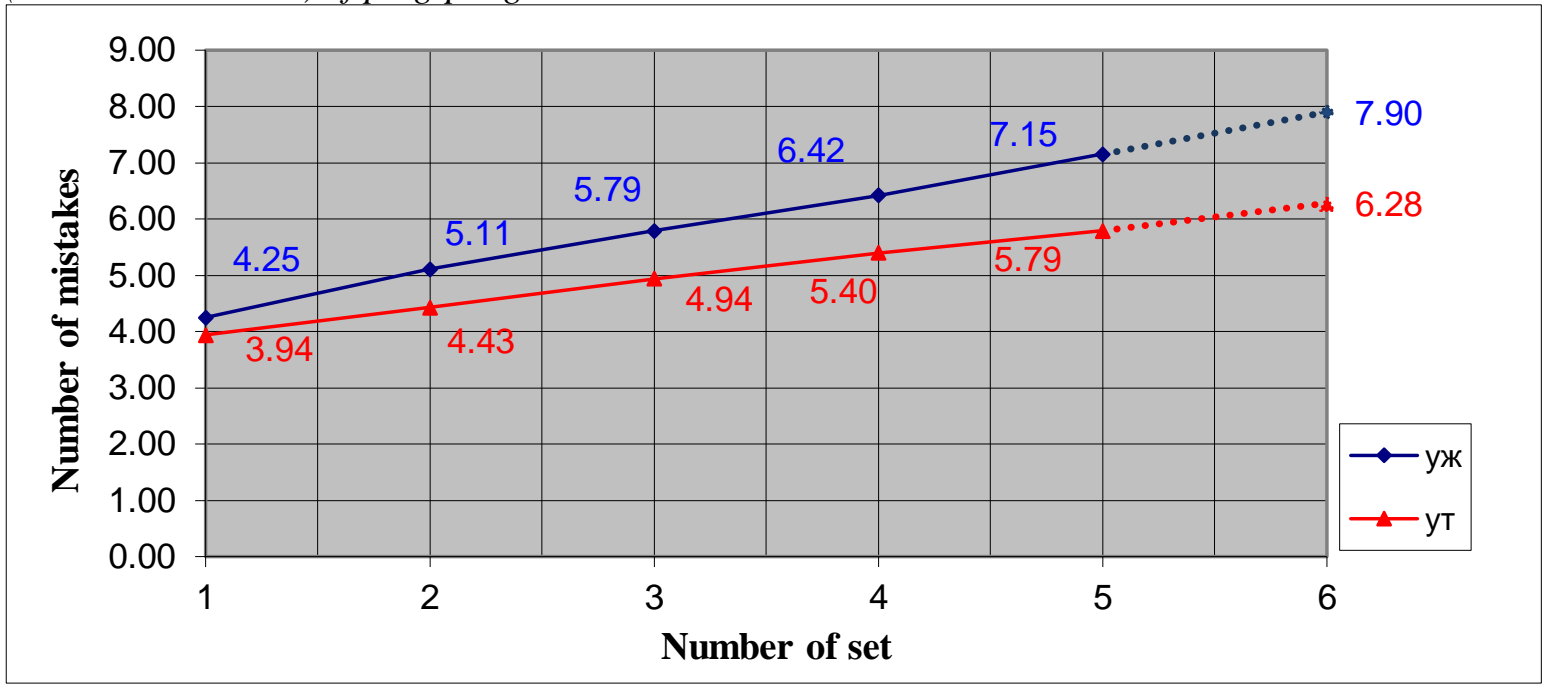

Figure 2. Comparative analysis of the numerical data of the control group when playing table tennis in October and May: yж-data for October, ym - data for May

As we see, the numerical data of the experimental group at the end of the experiment have a significant improvement: during the first set by 0,31 ; during the second by 0,68 ; during the third by 0,85 ; during the fourth by 1,02 ; during the fifth by 1,36 ; with a projected sixth set of 1,62. The level of reliability of the model is high, since the average error of approximation does not exceed $5 \%$ (in October $\mathrm{A}=0,97 \%$, and in May $\mathrm{A}=0,71 \%$ ).

Thus, for the first time: the effectiveness of a methodological approach to the development of a physical education program for students of groups with a sports orientation, combining the conventional means of developing physical qualities with an emphasis on special endurance; justified the program of physical education for students of groups with a sports orientation (sectional classes) Ping-Pong with the inclusion of aerobic activities (cross training and basic aerobics). Obtained results supplement scientific data on aerobic occupations and their influence on special endurance (Kudelko, 2004; Mardia \& Zemroch, 1984; Grinko, et al., 2017).

These results confirm the opinion that in the correct ratio of the physical fitness classes for students of groups with a sports orientation (sectional classes) and the inclusion of aerobic activities (cross training and basic aerobics), the special endurance of students can be significantly improved (Grinko, Kudelko, \& Hlotov, 2017).

\section{CONCLUSION}

An overall analysis, it can be concluded that analysis of literature sources showed that the problem of studying the influence of aerobic exercises for improving special endurance in groups with a sports orientation (sectional classes) Ping-Pong is not sufficiently studied. At this stage of the experiment it was proved that the inclusion of aerobic Ping-Pong (cross training and elements of basic aerobics) in the experimental group included in the training program on sporting orientation (sectional classes) significantly influenced the special endurance of the students than those engaged in the ordinary program (control group). Program on physical education on the basis of cross training and elements of basic aerobics for groups with a sport orientation (sectional classes) PingPong has been developed and justified, which essentially improves such physical quality as special endurance. With the improvement of special endurance, mobility and reaction rate improved.

\section{REFERENCES}

Ashanin, V. S., \& Pyatisotskaya, S. S. (2016). Statistical analysis of experimental data by 
Indonesian Journal of Learning and Instruction Volume 2, Issue 1, April 2019

means of spreadsheets EXCEL. Russia: KhSAPC, Kharkov.

Chaikovska, I. I. (2014). Application of modern information technologies for modeling economic processes on the basis of fractal analysis. Universytetski Naukovi Zapysky, (1), 378-387.

Dubnytskyi, V. I. (2011). Choosing the method for forecasting the value of securities, taking into account the fractal dimensionality of a number of observations. Biznes Inform: Nauk. Zhurnal, l(7), 120-121.

Grinko, V. M. (2015). Attitude of students to physical education and healthy lifestyle and their selfesteem of physical fitness. Slobozans kij Naukovo-Sportivnij Visnik, 45(1), 55-59. doi: 10.15391/snsv.2015-1.010.

Grinko, V. M. (2015). Classes of aerobic character and their possible impact on the level of general and special endurance of students. Naukovyi Chasopys NPU Imeni M.P. Drahomanova, 67(12), 42-45.

Grinko, V. M., Kudelko, V. E., \& Hlotov, Y. O. (2017). Training of students' special endurance in ping pong sport circles. Physical Education of Students, (2), 52-60. doi: 10.15561/20755279.2017.0201.

Kartashov, M. V. (2007). Imovirnist, protsesy, statystyka (Probability, processes, statistics). Ukraina: VPTs Kyivskyi universytet, Kyiv.

Kudelko, V. E. \& Korolinska, S. V. (2006). Analysis of socio-pedagogical foundations of the formation of needs in independent classes by physical culture at the students of the NFUU. Pedahohika, Psykholohiia Ta MedykoBiolohichni Problemy Fizychnoho Vykhovannia I Sportu, (12), 93-96.
p-ISSN 2614-8250, e-ISSN 2614-5677

https://journal.uniku.ac.id/index.php/IJLI

Kudelko, V. Y. (2004). Efficiency of organizational activity in the system of sports clubs. Fizicheskoe Vospitanie Studentov Tvorcheskikh Spetsialnostey, (3), 79-85.

Kudelko, V. Y., Shcherbina, Z. I., \& Pavlenko, Y. Y. (2003). Otsenka fizicheskogo sostoyaniya $i$ fizicheskoy podgotovlennosti studentov (Assessment of the physical condition and physical preparedness of students). Russia: NFaU, Kharkov.

Lemeshko, B. Y., \& Pomadin, S. S. (2002). Correlation analysis of observations of multivariate random variables in the violation of assumptions of normality. Sibirskiy Zhurnal Industrialnoy Matematiki, 5(3), 115-130.

Mandelbrot, B. (2004). The (mis) behavior of markets: A fractal view of financial turbulence, hardcover.

Mardia, K., \& Zemroch, P. (1984). Tablitsy fraspredeleniy $i$ raspredeleniy (Tables of $f$ distributions and distributions associated with them). Moscow: Svyazannykh S Nimi, Nauka.

Nayman, E. (2009). Calculation of Hurst's index for the purpose of revealing the trend (persistence) of financial markets and macro-economic indicators. Ekonomist, (10), 25-29.

Novikova, N. B. (2011). Fractal methods and the concept of economically minimal production systems in innovation management. Vest- nik YuRGTU (NPI), (2), 162-166.

Peters, E. (1991). Chaos and order in the capital markets. New York: John Wiley.

Plowman, S. A., \& Smith, D. L. (2011). Exercise physiology for health, fitness and performance. Lippincott Williams \& Wilkins. ISBN 978-07817-8406-1.

Weerahandi, S. (1995). Exact statistical methods for data analysis. New York: Springer. 


\section{Grinko Vitaliy}

An influence of aerobic activities on special endurance of students in groups with a sports orientation (sectional activities) of ping-pong 